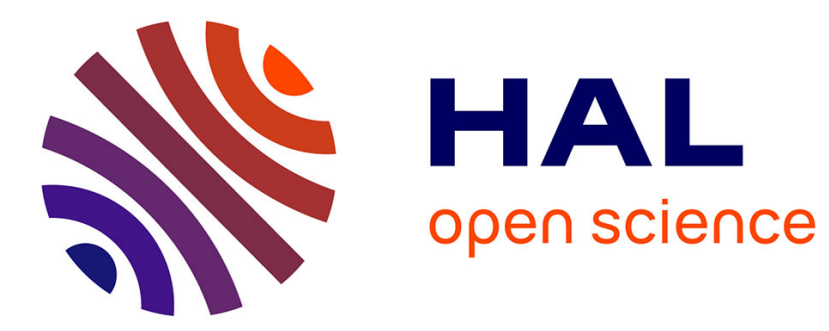

\title{
Slowing down modernity: A critique
}

Filip Vostal

\section{To cite this version:}

Filip Vostal. Slowing down modernity: A critique: A critique. Time and Society, 2017, 10.1177/0961463X17702163. halshs-01570100

\section{HAL Id: halshs-01570100 \\ https://shs.hal.science/halshs-01570100}

Submitted on 28 Jul 2017

HAL is a multi-disciplinary open access archive for the deposit and dissemination of scientific research documents, whether they are published or not. The documents may come from teaching and research institutions in France or abroad, or from public or private research centers.
L'archive ouverte pluridisciplinaire HAL, est destinée au dépôt et à la diffusion de documents scientifiques de niveau recherche, publiés ou non, émanant des établissements d'enseignement et de recherche français ou étrangers, des laboratoires publics ou privés.

\section{(1)(1) $\$(0)$}

Distributed under a Creative Commons Attribution - NonCommercial - ShareAlikel 4.0 


\title{
Peer-reviewed, revised and accepted version of article that appeared in Time \& Society, first published online: April 9, 2017 as \\ DOI: https://doi.org/10.1177/0961463X17702163
}

\section{When citing the article, please refer to the published version.}

\section{Slowing down modernity: A critique}

Filip Vostal

Centre for Science, Technology, and Society Studies

Institute of Philosophy of the Czech Academy of Sciences

Czech Republic

\begin{abstract}
The connection between modernization and social acceleration is now a prominent theme in critical social analysis. Taking a cue from these debates, I explore attempts that aim to 'slow down modernity' by resisting the dynamic tempo of various social processes and experiences. The issue of slowdown now accounts for a largely unquestioned measure, expected to deliver unhasty tempo conditioning good and ethical life, mental well-being and accountable democracy. In principle, there is little to object to in such well-intended goals. This paper, nonetheless, identifies several problems associated with slowdown, especially if presented as an incontestable doctrine. Despite its progressive feel, slowdown also stands for 1) a capitalist commodity; 2) a dangerous political objective that weaves together parochialism with fear-driven social sentiment; and 3) an undesired subjective experience. Finally, I evaluate recent propositions around 'accelerationism' and ask whether they might tackle the pitfalls of both social acceleration and slowness. I conclude by arguing that neither slow nor fast can be preferred as universal solutions.
\end{abstract}

\section{Introduction: fast modernity}

In spite of the present upsurge in literatures on the problems of social acceleration and deceleration, they both are far from new social occurrences; indeed they have been inscribed in modern rationality and modernization process. As Tomlinson (2007: 5-9) notes, acceleration in particular often features as an implied backdrop and contextual reference integral to influential argumentative constructs about modernity in both classical (e.g. Marx, Weber) and contemporary variants (e.g. Castells, Bauman). Another reason why acceleration and, to a lesser degree, deceleration, are now important objects of socio-cultural analysis and social critique is that they, rather than 
occupying an auxiliary position, are now understood as self-standing phenomena which are distinctively relevant and important in their own right.

Rosa (2013), to take a pioneering scholarship in this regard, offers a theory of social acceleration as a primary conceptual model and an explanatory instrument conductive to understanding the contradictory dynamic of modernization. Given that the constitution of modern societies and modern social processes are fundamentally temporal in nature, Rosa also uses his theoretical model for re-interpreting modernity as such; notably, the critique of acceleration comprises a strong component of his innovative theoretical scheme. Underpinning his critique is the main argument that the structural force of social acceleration lurks behind new forms of alienation, anomies and multiple socio-psychological pathologies as well as dysfunctionalities. Rosa's 'social acceleration thesis' (for a detailed critical discussion see Vostal 2014b) attracted important commentaries taking issue with its accuracy, character, foundations and epochalist nature (Archer 2014a, Savage 2014, Wajcman 2015). Rosa's theory is thereby often assigned the status of a 'zeitgeistological' sociological grid that allegedly disregards stability, fixity and 'freeze' of specific aspects inherent to modern capitalist logic.

Reflecting on Piketty's (2014) bestseller, Savage notes that 'there is actually a remarkable and enduring regularity which needs to be placed at the forefront of our understanding of contemporary - as much as classical - capitalism. Nothing much has changed, and in fact we are becoming rather more like our Victorian forebears than was the case fifty years ago' (Savage 2014: 598). Yet Rosa's assessment of the role of capitalist logic in the formation of social acceleration does not divert from Savage's position in any substantial sense: 'In the system of the capitalist economic system acceleration becomes an inescapable compulsion embedded in the material structures 
of society' (Rosa 2013: 161; see also Glezos 2012). From a temporal perspective, there are numerous regularities and immanent features integral to the capitalist system(s) that remain unchecked since Marx's and Weber's treatments (see e.g. Sayer 1991). Sewell in this respect notes: '[I]n spite of the birth and death of firms and industries, the transformations in technology, the development of ever more sophisticated financial instruments, the greatly increased capacity of states and repeated shifts in economic policy regimes, there is some central mechanism of capitalism that has remained essentially unchanged for a century and a half' (2008: 520). Notwithstanding the growing direct and indirect critical and empirical engagements with Rosa's theory of social acceleration (e.g. Schöneck 2015), Sewell's observation is important. It points to a fundamental attribute of Rosa's work which might often escape his critics who tend to highlight the epochalist and determinist features of social acceleration thesis, or sometimes even its fashionability, which will soon expire. Rosa states, similarly to Sewell, that acceleration is in fact an inherently conservative aspect of capitalism. Drawing on Offe, Rosa notes that the 'one characteristic that has existed as an unchanging "essence" or "formation trait" throughout all historical epochs and cultural appearances of capitalism and which therefore should be included in its definitions is that specific, peculiar, fatal connection of growth and acceleration, that "bicycle principle" of capitalist accumulation: either the process of circulation occurs at high and increasing speeds, or the system "falls over" (Rosa 2015: 77-8, emphasis original). The important remark that acceleration is a standard integral component of (capitalist) modernity, that it is something not extraordinary, remains rather sidelined in contemporary debates around the theme, which often account for acceleration as new structural process significantly co-shaping capitalist formations. It is, however, necessary to 
stress that the acceleration imperative is not one-dimensional: it is intertwined with both liberatory and progressive promises of modernity (Koselleck 2004; more generally Wagner 1994) as well as with the logic of capital accumulation (see Harvey 2006: 86; Postone 1993) and capitalist competition.

In this article, rather than continuing with appraisals of social acceleration thesis (see e.g. Vostal 2014a; Vostal 2014b; Vostal 2016; Archer 2014a; Wajcman 2015), I take a different, but complementary, stance and move the discussion into a cognate area. I analyze discursive practices of slowness, which the debate on social acceleration does deal with, but only tangentially. The reason for pursing this line of analytical inquiry is that slowness often is dialectically or consequentially related to acceleration, either as an unintended consequence ${ }^{1}$; or as a condition for further acceleration $^{2}$; or ideological reactions to speed-up (see Rosa 2010: 33-39). The analysis pursued below thus maintains the structural character of social acceleration as a crucial backdrop. ${ }^{3}$ The proliferation of slow discourse is also a manifestation of increasing dissatisfaction with both substantive (e.g. high-frequency trading, see MacKenzie 2014) and perceived speeding-up ('hurry sickness', see Levine 1997) in late modern societies. Also, and importantly, commentators such as Rosa and Virilio suggest that despite the omnipresent acceleration of time in late modernity, social formations and structures simultaneously exhibit 'frenetic standstill': processes, actions, experiences that transpire with increasing speed and transience, while society's deeper structures and formative frameworks, such as capitalism and the

\footnotetext{
${ }^{1}$ The 'overheating' - and consequential 'slowdown' - of the global economic system that resulted in the financial crisis of 2008 might be understood in this way. Another example is a simple traffic jam.

${ }^{2}$ Personal 'time-outs' and institutional 'pauses' for busy managers; in a social and political sense, various kinds of 'moratoria' are often suggested 'in order to solve some technological, political, legal, environmental or social problems or obstacles that stand in the way of renewed processes of modernization' (Rosa 2010: 37)

${ }^{3}$ Although human agency and the ability to organize, coordinate, juggle and craft time accounts for an important explanatory dimension of social temporality and time experience (see Flaherty 2011), it is not extensively considered in this article.
} 
secular belief in progress, remain static 'immobile' principles. To this end, Wajcman notes that the present scholarship overly focuses on speed and neglects that 'speed and slow down have always coexisted in modernity' and it is 'the meanings and values attached to them [that] have shifted' (2015: 173, emphasis added).

In a discursive sense, speed, in modern society, continues to be both valorized not only as a propellant of the capitalist dynamic (Glezos 2012: 85ff) but also through the connection with arch-modern ideas of progress or as a virtue associated with wit and intelligence (see Collins 2014: 54-55). It is mostly, however, condemned by cultural and social critics (as something incompatible with democracy's operations, cognitive capacity of human brains, social and natural reproduction). Simply stated, there is a powerful cultural discourse maintaining speed as a juggernaut limiting human well-being, jeopardizing progressive social development and reproduction, and negatively impacting nature and ecological systems. Slowness is then depicted as a desirable and necessary antipode to the 'evil' fast world, and is underpinned by positive and emancipatory connotations. ${ }^{4}$ In both popular (see Honoré 2004) and academic discourse (see Berg \& Seeber 2016) agitation for slowdown now resonates substantially.

In the remainder of this article I argue that the present conceptions of slowness, the modes of reasoning underpinning it and the emerging forms of slowness are problematic because the slow is not necessarily the equivalent of poise, deliberation, long termism, duration, maturing, and consequently human betterment. The key point I will make can be outlined as follows: while speed up (as, for instance, an involuntary reaction to time-pressure) is undoubtedly a significant social and psychological issue, 'going slow' - as presently conceived - does not account for

\footnotetext{
${ }^{4}$ Yet slowness is also oftentimes perceived as regressive and unpractical (often equated with laziness, procrastination but also with a lack of intellect and intelligence - see Nadolny 2004).
} 
viable solution to the pathologies of social acceleration nor does it account for an instrument bypassing the present capitalist constellation. I would like to offer three provisional, but nevertheless supportive critical points for this argument: first, I will show that slowness can actually be conceptualized as an exploitable commodity in contemporary capitalism; second, I will highlight the problematic relationship between slowness and localism; and third, I will briefly look at slowness as an undesired human experience. Finally, I briefly assess recent propositions surrounding 'accelerationism' and ask whether they might tackle the pitfalls of both social acceleration and deceleration.

\section{The agenda of the slow}

Thinking about social slowness as a distinctive theme in the social and human sciences is rare (for notable exceptions see Parkins \& Craig 2006; Osbaldiston 2013a; Koepnick 2015) and on such occasions the defence of slowness is often counterpoised against the objective or supposed acceleration of social life: 'People are reacting against "fast capitalism" in a way which embraces meaningful or even authentic relations with environment, people and the self' (Osbaldiston 2013b: 11). This is not such a surprising logic, already identified by Rosa and scholars who investigate his 'social acceleration thesis' in specific social environments (see Korunka \& Hoonaker 2014; Müller 2014; Vostal 2015b).

Against the background of the scholarship on fast modernity gestured upon above, it is possible to identify three contextual and interpretative modalities arguing for slowness: realistic, political and cultural. Slowness is often understood in realistic terms and as a natural principle or given - there are numerous human activities, phenomena, experiences and processes that practically and/or physically cannot be 
sped up and that always assume a necessary temporal duration, for instance biological process of pregnancy. Also, and somewhat naturally, many cognitive, learning and socialization processes often need time and relative slowness. Politically, several arguments around the temporality of democracy have recently emerged (e.g. Wolin 1997; Scheuerman 2004; McIvor 2011) and are often centred around the assumption maintaining that if democratic institutions are to meet their liabilities and raison d'être, their operations cannot be subsumed to the social acceleration dynamic and need to remain 'slow'. However, these commentators seem to underestimate the resilience and 'adaptive potential' (Saward 2015: 18) of democracy in the conditions of social acceleration. Saward's account adds an important contribution to this debate through nuanced arguments developing 'slow democratic design' and highlighting political agency of different actors within the democratic system who "can often deploy and manipulate temporality' (2015: 17). Even if he adheres to the notion of 'the slow', his account bypasses both the determinist understanding of social acceleration as well as gestural pleas for 'slow democracy' by advancing a set of recommendations and arrangements (see Saward 2015: 12-17) for time-sensitive democratic politics in the conditions of accelerated modernity. Culturally, being slow is frequently associated with wisdom, meditative styles of argumentation, discussions in intellectual environments (see Pels 2003). In a similar vein, creativity and inventiveness are thought of as inherently slow activities. Relatedly, many 'oases of slowness' (digital detox courses, life-coaching, therapies, meditations of various blends) are presented as a refuge from our busy everyday lives. The realist and cultural and, to a lesser degree, political axes account for an emerging ethic of slowness that begins to form disorganized, interim and porous discourses aimed at the 
spectrum of pathologies of fast modernity, simultaneously providing a desired exit from the seemingly inescapable speed 'trap' (Taylor 2014).

Yet the definition of the ethic of slowness is largely avoided and/or vague in existing accounts. Parkins and Craig, for that matter, conclude their study on slow living in this manner: 'Rather than defining slow living by its practices ... we have proposed that slow living is a way of cultivating an ethical approach to the everyday. Thought of in this way, slow living becomes as much an attitude or disposition as an action, one that combines wonder and generosity' (2006: 139; see also Osbaldiston 2013c: 178). Honoré, perhaps the most important proponent of slow ideology, never ceases to advocate the ethic of slowness as an all-purpose good and near-redemptive counter-measure against accelerated modernity. Though Honoré qualifies that slow down is not about slowing down to a 'snail's pace', but about finding the right speed (e.g. 2013: 289-290; see also Honoré 2004), his bestsellers always begin with an easyto-swallow diagnosis of contemporary modernity, with 'bad' speed at its epicentre. His recent criticism of society's alleged en masse obsession with 'quick fixes' is as follows:

Everywhere you look - health, politics, education, relationship, business, diplomacy, finance, the environment - the problems we face are more complex and more pressing than ever before. Piss-poor performance is no longer an option. The time has come to resist the siren call of half-baked solution and short-term palliative and start fixing properly. We need to find a new and better way to tackle every kind of problem. We need to learn the art of the Slow Fix (Honore 2013: 11-12).

Moreover, Honoré's ‘empire of slow' often serves as a backdrop and even intellectual resource for various slow movements, no matter if they bear more resemblance to a lifestyle, middle-class convivial encounters of slow cooking or, even indirectly 
progressivist anti-globalization agendas, sometimes of the Marxist anti-capitalist variant.

In Seventeen Contradictions and the End of Capitalism, Harvey proposes, as part of his overall anti-capitalist struggle and politics, that we should 'should strive in a world in which ... daily life is slowed down - locomotion shall be leisurely and slow - to maximize time for free activities conducted in a stable and well-maintained environment protected from dramatic episodes of creative destruction' (2014: 294-5, emphasis added). Regardless of his well-intended point against the 'creative destruction' integral to capital's domination in social life, these islands of slowness, intentionally slow segments of life and slow ideologies not only already exist but, moreover, proliferate. Slow initiatives are not necessarily new in the history of capitalist modernity, ${ }^{5}$ and even though, as suggested above, capitalism does thrive on speed (see e.g. Koepnick 2015: 2), it also needs 'slow zones' - for innovations, for spaces where labour can 'recharge', for downsized areas that would contribute to capitalism's further acceleration (see Vostal 2016: 58-61 and below). Admittedly the appeal of slowness in the fast world and its supposed connection with calm, meditation, idleness, stillness, refuge from permanent connectivity is difficult to deny. Yet, slow initiatives seem to, more often than not, 'sell' slowness rather than provide it as an intellectual or educative compound or as a democratic space of practices resisting the escalatory logic of modernity (Rosa 2014: 43). ${ }^{6}$

\section{Slowness: for sale}

\footnotetext{
${ }^{5}$ Indeed, attempts to revolt against/resist social speed are not unique to late modernity. Walter Benjamin, for instance, famously noted how mid nineteenth-century flâneurs resisted the increasing pace of modern life by taking turtles - to set a slow pace - for walks in the streets of Paris.

${ }^{6}$ However, I am not ready to strictly deny the utopian potential of some slow initiatives that might operate outside and against the logic of capitalist subsumption.
} 
Part of the problem lies in a particular discursive framing of the allegedly 'dangerous' acceleration of modernity, particularly if presented as ubiquitous, inescapable and as a determining 'iron-cage'; as something approaching emergency (for a vivid description of the imaginary feeding 'the fear of fast planet' see Glezos 2012: 1-16). Under such auspices and within this interpretative 'matrix', slowness, stillness and calm come across as something desirable, as something needed, as something partially or fully redeeming the ills of the speedy world; as a 'first aid kit' providing refuge from the aimless acceleration that characterizes the present. Yet, as Osbaldiston notes, this kind of relief never comes for free: 'across the world, downshifters, seachangers or lifestyle migrants have demonstrated this through their willingness to give up the consumerist life style for simpler existences, sometimes in completely new locations' (2013b: 6). Of course the possibility to 'give up' the consumerist, and arguably fast, metropolitan lifestyle, is not a matter of democratic choice but often assumes material dispositions and class status. Osbaldiston seems to point towards a general trend of reification and co-optation - as famously conceptualized by Lukács and Marcuse ${ }^{7}-$ of slow initiatives. All sorts of 'reliefs' - those opposing accelerative dynamics of modernity - are now promoted and offered in a marketplace. The adjective slow slow food, slow travel, slow sex, education, learning, communication and many more - might actually function as distinctive brands offering some kind of slowness, but as private and consumerist commodities rather than anything approaching a productive oppositional (or dissenting) stance against social and individual pathologies of acceleration such as time-pressure, rush, information overload and permanent connectivity, or 'iDisorders' (see Rosen 2013).

\footnotetext{
${ }^{7}$ Boltanski \& Chiapello (2006) similarly argue that critique of capitalism in fact - paradoxically - turns out to be one of the driving forces of capitalist reproduction.
} 
Hence, slow living is now 'for sale' and approaches a consumerist lifestyle mostly for middle-class metropolitan dwellers - the majority of whom are probably far from holding transformative, progressivist or even socialist agendas. Arguably, many would admit that 'it all needs to slow down', but such slowness would then be, more often than not, consumed, and consumed privately. Archer (2014b: 5) is correct when she says that "downsizing" and "downshifting" to a slower pace of life are luxury options available only to the better-off.' One of the most vocal and visible global platforms promoting slowness is The Slow Food Movement (SFM) (see Petrini 2003; also Andrews 2008) that capitalizes on the wide-spread social sentiment of 'hurry sickness' and accounts for one of the most distinctive protest movements against social speed. Hsu (2015: 629) insightfully notes that the character of the SFM might be interpreted in several ways: as a rival to unhealthy and industrial-production driven 'fast food'; as a 'parcel of the anti-globalization movement' which opposes convergence of diverse food cultures; as a site preventing 'social isolation' through advancement of communal events organized around food preparation and consumption; and as 'broader political movement to safeguard the amount of biodiversity that is left on the planet.'

To be fair, the SFM does maintain a residual progressive edge and its origins contain important references to the Italian communist movements of 'workerism'/operaismo/autonomismo (see Andrews 2008), but the question remains as to what extent this kind of referential strategy and even practical conduct veils the contemporary elitism of the entire slow discourse. Osbaldiston recognizes this tendency when he notes that "Slow Food" has become a significant institution which has all the trimmings of a modern day corporation, minus the sense of capitalist greed' (2013c: 178-9). Slowness in this sense can be understood as an ideological 
mystification - a real appearance, in the words of Sayer (2000) - that conceals the logic that not only gives rise to social acceleration (i.e. capital accumulation, growth, competition), but may also function as a legitimization strategy for existing capitalist structures and practices and consequent oppressions and inequalities.

Slowness advanced in this form is indeed not a normatively promoted social right that one would be entitled to (is that even desirable?), but rather, as it seems, a relatively expensive commodity. Consumers of slowness simply need material resources to 'buy' slow time - for living, cooking, communicating, walking slowly, for being disconnected from fast information and communication technologies (ICTs). There are, in fact, clearer and bare evidences that slowness can be understood as a commodity. Drebitko, founder of another iteration of slow ideology, The Slow Living, says: 'I coined the term Slow Living as a consumer behaviour philosophy that translates across product categories (food, travel, home and garden, health and beauty) into purchasing decisions based on a common set of product characteristics. ${ }^{8}$ A recent example of slowness-as-commodity is 'slow watches' (see Picture 1). It aims to give the impression that time runs slowly and there is always enough of it - at a price of $€ 260$. As the enclosed manual says: 'I'll be your loyal companion as you journey through a whole new life - one where you learn to be slow. ${ }^{9}$ The problem is that not only the mere commodification of the slow brand, but also the watches themselves set out to impose a different temporal sensitivity, which is at odds with and only partially complying with the dominant clock-time regime, and the standard 'reading' of time. ${ }^{10}$ Indeed it might be a fascinating end to create the community of

\footnotetext{
${ }^{8}$ See http://www.slowlivingtoday.com/about/

${ }^{9}$ For more see https://www.slow-watches.com.

${ }^{10} \mathrm{I}$ have personally experimented with slow watches and used them for a week. The idea is that slow watches 'displays the entire day ... and makes you visualize time in a more natural way. Live for the moment rather than chase every minute or second.' The slow watch (see Picture 1) '...only uses one hand - the hour hand. This allows you to read the time precisely enough, just not every second.'
} 
'slowers' and, in the words of the founders of the brand, to 'slowify the world', yet it seems that it would be a community of privileged individuals who not only can afford such accessories but, more importantly, who can adopt a different temporal reading of clock-time where punctuality and exactness are negligible.

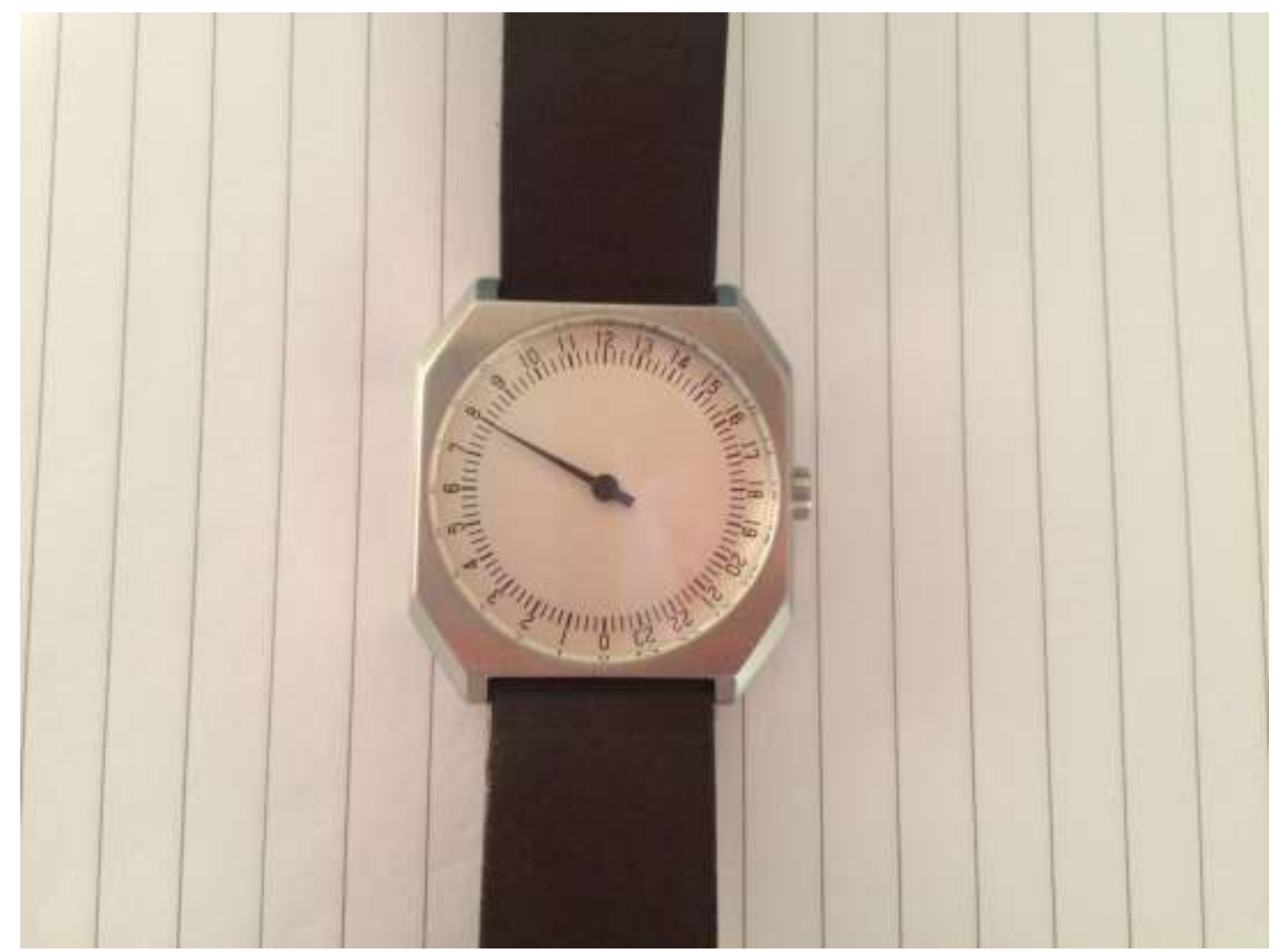

Picture 1 (photo by Filip Vostal)

Similarly as Heath and Potter (2005) (who draw on Lukács, and mostly on Marcuse) maintain in their book The Rebel Sell, many contemporary counter-cultural movements with their distinct cultural politics - and some slow initiatives approximating or even embodying such characteristic - become new grounds for capital accumulation and consolidation strategies. Slow products and 'services'

(adopted from https://www.slow-watches.com/the-brand). However, slow watches proved to be rather useless for my time organization as when I wanted to know what time it was exactly I never managed to capture it and had to check my mobile phone (not to mention the tiny size of the digits). As a result slow watches become rather impractical in modern societies where clock-time reading is a universal coordinating and scheduling mechanism. 
appear as paradoxically integral parts of such fast capitalism, which many critical theorists identify as the sole driver of social acceleration (Koepnick 2015: 2-3).

Rosa notes a crucial complementary, somewhat traditional Marxian feature here: he identifies how slow initiatives can account not only for ideological reactions to the accelerating world but also - paradoxically - for 'accelerators' in their own right. In other words, slowness can be understood as a functional precondition for further acceleration. Slow zones may provide spaces of chill-out where one can gather energy and momentum to be an ever-more productive and effective 'component' necessary for the 'smooth' functioning of the accelerative capitalist machinery. ${ }^{11}$ In this sense 'recharging' practices and time-out zones of slowness form dramatically evolving profitable industries of life-coaching, traditional counselling and alternative therapies.

\section{Parochial slowness}

The second variant of my critique deals with the relationship between localism and slowness and is qualitatively different from the one above, but there will be occasional overlap. Also, my understanding of localism is different from the dominant conceptions that often relate slowness and localism in progressive and salutary ways (Carp 2012; Saward 2015). The critique I offer partially draws on neo-vitalist approaches by Connolly (2002) and Glezos (2012) who note that slowness can actually be an integral component of a brand of particular populist folk politics, which is stressing nationhood, (quasi-)religious purity and national unity usually grounded in shared tribe-like or kin-like national-cultural imaginary about the group's past that allegedly existed some time in the past. This localist politics of slow seeks to re-

\footnotetext{
${ }^{11}$ A caricatured example is a 'power nap' that some employers allow to be taken during the workday, after lunch for instance. The rationale is that a 'fresh' worker should increase his/her performance and productivity.
} 
establish and stabilize local and immediate 'secure' identities by offering putatively safe grounds free from disturbing and unwelcome external elements that are depicted as jeopardizing parochial mindsets and reasoning. The external elements are often couched as if they are coming from the outside and distant, dangerous worlds; they are presented as dramatically fast, often uncontrollable and unintelligible. The examples of such often media manufactured ${ }^{12}$ threats involve alarmist portrayals of the unchained inflow of migrants or scapegoating of other socially marginalized people who allegedly threaten local communities and traditions, or can involve a construal of 'evil' regional or national power silos (Brussels, Washington, Berlin) existing somewhere beyond the reach and making decisions on the behalf of local constituencies.

From Japan to the US, and indeed within the EU, we can presently observe the empowerment of populist, chauvinistic and xenophobic formations promoting some form of the localist slowness. In 2015 we can register a sharp increase of such cultural and political tendencies in relation to refugees seeking asylum in Europe. This is indeed accompanied by abounding regional nationalism, Islamophobia, calls for closing borders, sealing national and cultural territories and convulsive protectionism from 'the other', from the Simmelian 'stranger' (see also Bauman 1990). ${ }^{13}$

Those formations deploy rhetoric which is appealing to a localist mindset: slow and sedentary practices, often rituals, associated with local ceremonies, festivities, convivial events cementing local identities, local 'totems' sustained by home-made spirits and folk costumes used as counter-punches against the alleged threat of social speed-driven dynamics of both multinational capital and displaced

\footnotetext{
${ }^{12}$ Mass media framing indeed plays a very important role in such constructions.

${ }^{13}$ Brexit can be understood along these lines. It partially turned into voting against 'fast-moving' migrants and EU politics and for 'slow' protectionism and isolationism of the UK, and local decisionmaking capacity in an economic, cultural and political sense.
} 
persons. I am not suggesting that local slow traditionalism is reducible to such an interpretative framework (tradition also works as a strong social bond: carnivals can be subversive and liberating as we know from Bakhtin), but I rather highlight its potentially dangerous and undemocratic edge. Furthermore, the convulsive advocacy and campaigning for the local, the provincial, the parochial, the authentic, the traditional and the like is arguably underpinned by flawed, or at least incomplete and far too emotionally charged interpretations of social speed. That is so for two reasons.

First, the imaginary of the external fast world as threat is sustained by the common - and largely incorrect - perception of social speed. In public discourse and academic discourse too - social speed is often represented as something homogeneous, with fixed logic and, importantly, as something distinctively negative and oppressive - usually as a part of some looming emergency or 'ticking bomb' (Glezos 2012: 10-42) we need protection from. As many commentators remind us, social acceleration - despite being inscribed in the logic of modernization - is not only inherently uneven and relational, but also dramatically heterogeneous. Different relevant sociological variables - gender, class, ethnicity, profession, age - enter into the experience and workings of the acceleration dynamic. In other words, social acceleration is asymmetrically distributed and manifests differently in different social arenas. Second, acceleration is a deeply modernist and progressive principle - as Koselleck (2004: 12, 24, 42) noted: at the outset of modernity, to accelerate meant (and residually still means) to emancipate oneself from the clutches, if not of oppression, then of the imperative of tradition; social acceleration signaled the progress of human reason. To accelerate had been closely connected to selfempowerment, development and to the open future. Acceleration often also brings comfort and convenience; acceleration also means energy, excitement and thrill. 


\section{Against sluggishness}

On the level of individual experience, slowness can be openly refused as regressive, unproductive and simply undesirable. To illustrate the point, we can use the mushrooming slow initiatives apparent in contemporary academia - many of them direct offshoots and extensions of the ideology of slow: slow academy, slow science, slow professor, slow scholarship. Even though a number of initiatives connect the principle of slowdown with a direct and productive critique of neoliberal assumptions that underpin current academia (see e.g. Berg \& Seeber 2016; Mountz et al. 2015), it remains questionable whether slowness accounts for a desirable principle to follow in academia and whether 'slow scholarship' represents a foundational tenet upon which a solid resistance against accelerating business-driven managerial academia might be built. According to my empirical work conducted in the UK (Vostal 2015a; Vostal 2015b; Vostal 2016) and the subsequent ethnographic project on academic time I am currently engaged in in the Czech Republic, many scholars and scientists do not plead for slowness as such (at least not in any significant sense), but rather they ask for a modest temporal autonomy as well as for uninterrupted periods of time for research concentration and preparation. Such principles should then be two-fold: experiential and institutional, both involving protection of 'unhasty time' (Pels 2003), and relative sovereignty over scheduling, planning and organization of research activities. One of the fundamental concerns expressed by academics driving the calls for temporal autonomy seems to be interruptive 'time-thieves' - administration and management tasks - typical for research bureaucracy at the expense of time that would ideally be available for activities related with the very research. Even if the concept of temporal autonomy comes here only in passing, it remains a challenge in terms of designing 
(cf. Saward 2015) a politics of temporality in academia and what exactly such politics would entail.

Moreover, it is not uncommon that many scientists consider slowness a regressive principle - scientific conduct, after all, needs to 'keep up' with the world it investigates while, of course, maintaining some sort of delaying tactic in organized critical reflection and analysis. Sluggishness, inability to proceed, to progress, to produce (e.g. texts, experimental results) is not something desirable and appreciated in the academic and scientific environments. The same is valid for the notoriously slow pace of academic publishing and the relative frustration it often generates, especially in this digitally savvy age:

The slow pace of academic publishing is often painful to witness, particularly for the $21 \mathrm{st}$ century, when everyone is used to the nearly-immediate broadcasting of everything. Academic systems of appraisal, promotion and research funding allocation also define hectic schedules, and the competition between highly-qualified candidates is ferocious. The traditional submission to publication times in the arts and humanities is increasingly unfit for the purpose of addressing the increasing pressures by funders and Higher Education employers for researchers to "perform" and have "impact". (In the case of scholars working on themes and methodologies that are always changing, the slow pace is indeed counterproductive and might jeopardize the quality and relevance of the research once it finally gets published.) Current technologies enable, up to a certain extent, faster editorial workflows, but publishing and communication technologies also play a role in increasing the already heavy workload of many academics (Priego 2013).

The heavy workload Priego refers to is often accompanied by more positive experiences of speed in academic life. On a more phenomenological-psychological level, academics and scientists often embrace a number of what we might call 'moments of fruitful acceleration'. These are mostly associated with discovery, 
brainstorming, aha-moments, eureka moments. Many also equate acceleration with intuition, which cannot be taken as basis for scientific work, but as Bachelard (2002) indirectly notes, can serve as the main impetus for further - and perhaps slower and reflective - scientific practices. Perhaps iconically, we can say that Archimedes in the bathtub and Newton under the tree experienced a 'moment of fruitful acceleration' of their trains of thought. Moreover, and in a more practical sense, due to the dramatic proliferation of fast research engines and other scholarly Internet tools the 'access to scholarly information and research results has never been easier; and thanks to the vast computational power now readily available, whole new areas of scholarly investigation have been opened up (Levy 2007: 237). In recent years, fast social media such as Twitter have turned out to be very productive and practical instruments in academic life - useful for promoting one's work, networking with colleagues globally and enhancing scholarly impact (see, above all, Carrigan 2016).

\section{The brave new world of accelerationism}

Now, can the opposite - labelled as 'accelerationist politics' - offer something of an alternative and progressive avenue? Accelerationist politics is a belief that the only radical response to the unsustainability of contemporary capitalism is the acceleration and, by extension, exacerbation of its underpinnings, alienating features, embedded contradictions and pathologies. At the same time the gains of the capitalist system such as ubiquitous technoscientific infrastructures - are to be channeled to different goals, rebalanced and repurposed, not merely rejected. It is difficult to straightforwardly refuse this accelerationist politics. Accelerationists highlight the fact that there is a real subsumption of life under capitalist relations; they also side with the emancipatory dynamic that broke the chains of feudalism at the outset of 
modernity - these principles seem intuitively attractive for progressivist thought. In this vein they maintain that "contradictions and absurdities of capitalism have to be countered with a politically and theoretically progressive attitude towards its constituent elements' (Mackay \& Avanessian 2014: 4). In contrast with the majority of critical theorists of speed who only provisionally discuss the question of slowness, accelerationist thinkers explicitly reject the principle of deceleration as the resistance technique and counter-stance towards modern acceleration. They claim that such rejection of technological infrastructures wrought by the axiomatic logic of capital accumulation and exchange value might be redirected for progressive and emancipatory political ends. In fact, the proposition pursued by accelerationism is the very opposite of slowdown, i.e. to speed up to the limits of possibility.

In \#ACCELERATE MANIFESTO for an Accelerationist Politics (Williams \& Srnicek 2014) ${ }^{14}$, accelerationism is traced as far back in time as to Marx. Moreover, accelerationist thought underpinned by accepting the interconnectedness of technological edifice and economic system maintains that

[t]he speculative extrapolation of the machine process, the affirmation that this process is inextricably social, technical and epistemic; the questioning of its relation to capitalism, the indifferent form of exchange-value and its corrosion of all previous social formation and subjective habits; and its effect upon culture and the new possibilities it opens up for the human conceived not as eternal given, fated to suffer the vicissitudes of nature, but as a historical being whose relation to nature (including its own), increasingly mediated through technical means, is mutable and in motion (Mackay \& Avanessian 2014: 11).

\footnotetext{
${ }^{14}$ It can be characterized as a leftist political proclamation conceptualizing social progress beyond "traditional critiques and regressive, declarative or restorative "solutions"' (Mackay \& Avanessian 2014: 7).
} 
The crucial principle for accelerationists thus lies in an attempt of 'reshaping and repurposing (rather than rejecting) the technologies that are the historical product of capitalism' (Mackay \& Avanessian 2014: 23). One of the most important points this body of thought makes - as well as an argument upon which its critique of capitalism is grounded - is that present capitalist logic sustained by neoliberal rationality is no longer a dynamic or progressive force but a deeply regressive one (leaving aside the question if it ever was and, for the moment, its unintended environmental and psychological consequences). Accelerationists also profess criticism towards contemporary and dominant left political discourse which, according to them, is technologically illiterate, overly 'metaphysical' in nature (many radical leftist thinkers and movements maintain that there is some kind of 'outside' of capitalism), characterized by defeatism, inertia and parochial quarrels.

Glezos (2012) offers a similar, yet considerably more sensitive 'way out' of the acceleration vs slowness dilemma. However, his interpretation is far from conceiving it as an agency-less mega-force of modernity, but, in addition to being a threat, speed is also an opportunity to be embraced and tailored to democratic praxis. Drawing on Deleuze \& Guattari and the vitalism of Bergson he argues that embracing and using technologically induced acceleration might provide possibilities to produce a safer, more egalitarian, pluralistic and democratic world. Glezos rehearses a compelling argument claiming that if recast into political decision-making and polity, a compulsive and flat rejection of acceleration in fact stands for a reactionary and resignatory undemocratic practice (re)producing (symbolic) violence, (social) inequalities and hardship. The approach Glezos adopts towards speed - in which he perhaps unintentionally identifies the motivational force behind many calls for slowness - sustains that: 
the tendency to apocalyptic thinking with regards to the question of speed (the tendency to view acceleration as a deterministic line that could be politically engaged with only in futile efforts to turn back the clock) ... [is] ... rooted not in the material facts of acceleration ... but in a sense of ressentiment against futurity and exteriority, a calcified resentment against the uncertainties and contingencies which an open future and open borders inevitably bring (Glezos 2012: 186).

Notwithstanding the viability of Glezos's position refusing to perceive speed one-dimensionally, i.e. solely as an oppressive instance, embracing fast technologies also means embracing them in their materiality. Importantly, it is not only that ICTs have become already standard, embedded - and unquestioned - features of democratic politics, but also the very fact that such process should be reinforced and deepened as Glezos maintains. He further argues, implicitly opposing the excessive negative preoccupations with speed, that it [speed] and 'accelerative technologies present potential sites of resistance and possibility which can be deployed against exploitation and inequality' (2012: 89). In other words, the use of fast ICTs could be redirected to democratic practice and 'liberated' from their commodity status. Glezos's point holds even more acute, if slightly problematic, once we yield to the interconnectedness of technological progress and capitalist rationality.

Despite this position being generally sympathetic in its overall ambitions of embracing the present technological possibilities for emancipatory purposes, its aim omits the very fact that the technologies we use never operate in a social vacuum and are always integral to the workings of socio-economic reproduction mechanisms. Noys (2014) argues that accelerationists, for instance, in a strange way resemble a hybrid of the Futurists and Soviet communists in how they integrate forces of capitalist production as forces of their own destruction. The question thus remains as to whether radical inequalities and other integral pathologies of capitalism will be 
'taken with' the utopian anticipations of those embracing technological acceleration it is very difficult to dissociate unintended implications of capitalist system and its technological makeup. The main problem therefore seems to be the inextricable link between capital accumulation and technological development. The practical enactment accelerationist scenario is (and will probably remain) barely possible beyond the level of conceptual imagination: it would be difficult to 'destroy' (via repurposing) capitalism by accelerating its negative tendencies - alienation, inequalities, inhumanities and the like - without destroying not only the technological infrastructure but much more. Rather than the accelerationist scenario it might be more useful as well as practical to explore the - slightly more realistic - possibilities associated with the notion of a 'post-growth' society (see Rosa et al 2016) and render the 'dimension of time as a starting point for the "pacification"' (Rosa et al 2016: 17) of crises of capitalist modernity.

\section{Conclusion: towards a normative ambiguity}

There is little doubt that social acceleration accounts for significant motion in modernity. Yet the dynamics of social acceleration itself as well as reactions to it are far from even and one-dimensional. The ambivalent view of speed and slowness advanced in this article builds and adds to the existing debates of social acceleration by developing a nuanced critical account of slowness. The main aim of this line of inquiry is to stress the ambiguity inherent to slowness that has so far remained overlooked in the scholarship on the slow that, more often than not, tends to embrace slowness unreservedly. The fast (bad) vs slow (good) dichotomy seems now to be an emerging dualism in debates around social temporality where the slow is often advocated as a solution. By advancing my analysis I strived to problematize this 
perspective and stressed questionable aspects associated with the mushrooming slow discourse. I am not rejecting the slow altogether, but rather critically highlighting its other, relatively sidelined, dimensions.

Some acceleration commentators say that slowness proper can be approximated only if the character of capitalism changes (Connolly 2002). This, we know, remains one of the most challenging problems of contemporary social and political thought. Slow living initiatives seem to have so far failed in achieving such goals beyond affecting individualized lifestyles of fragmented groups of people; slowness can also be a rather dangerous component of localist and undemocratic political agendas; many individuals prefer and welcome acceleration rather than slowness in their ways of living and working. Even if these barriers are somehow overcome, the return to some kind of slow world still appears as a restoration of the pre-modern configuration. On the other hand, accelerationist politics and embracing ICT-driven acceleration possibilities remain inherently problematic. Is an acceleration-less modern condition even desirable, given acceleration's modernist connection with emancipation, self-determination and self-empowerment? Is it not the case that both acceleration and slowness deliver comforts and conveniences? Shouldn't we begin to think beyond the dichotomy of fast and slow as Hsu (2015) suggests and perhaps establish an idea of time autonomy as a serious matter for political, ethical and psychological discussion? This might be a minor, yet first necessary step towards the opening up of the conditions of possibility of how to articulate a way out of the apparent deadlock of oppressive and detrimental social acceleration on the one hand, and the notion of slowness which so far ceases to account for progressive social principles on the other. In light of these observations it might be productive to begin to think about the 'normative ambiguity' of both fast 
and slow, which also characterizes many other important concepts in social theory (see Pels 1998). It is probably difficult, if not impossible, to argue for an essentialist or linear theory of fast and slow because their positive and negative aspects are invariably tied together (e.g. duration, demanding time, taking time are not necessarily synonymous to being slow and might comprise 'fast moments'). Rather than absolutism of either/or we might approach the dichotomy with epistemological moderation: due to their normative ambiguity neither slow nor fast can be preferred as universal solutions.

\section{Acknowledgements}

I would like to thank Libor Benda, Marc Bessin, Mark Carrigan, Gregor McLennan, Dick Pels, Clara Royer, Xing Su, Tereza Virtová and three anonymous reviewers for their insightful and helpful comments on earlier drafts of this paper. I also received valuable suggestions from participants of the Philosophy of Social Science Conference, Prague, May 22-25 2014, from attendees of the CEFRES/IMS FSV UK seminar Between Disciplines and Areas, Prague, December 142015 and from the participants of BSA 2016 Theory Stream Roundtable Discussion, April 7-9 2016. This work also benefited from my 2015-2016 postdoctoral stay at CEFRES (Centre français de recherche en sciences sociales/French Centre for the Research in Social Sciences) in Prague.

\section{Funding}

The work on this paper was supported by the postdoctoral fellowship CEFRES USR 3138 CNRSMAEDI and by the grant no. 16-18371Y awarded by the Czech Science Foundation.

\section{References}

Andrews G (2008) The Slow Food Story. Politics and Pleasure. London: Pluto Press. 
Archer M (ed) (2014a) Late Modernity: Trajectories Towards Morphogenetic Society. Dordrecht: Springer

Archer M (2014b) Introduction: ‘stability' or 'stabilization' - on which would morphogenetic society depend? In Late Modernity: Trajectories Towards Morpohogenetic Society edited by M Archer. Dordrecht: Springer, pp. 1-20.

Bachelard G (2002) The Formation of the Scientific Mind. The Contribution to a Psychoanalysis of Objective Knowledge. Manchester: Clinamen Press.

Bauman Z (1990) Modernity and ambivalence. Theory, Culture \& Society 7(2): 143169.

Boltanski L \& Chiapello E (2006) The New Spirit of Capitalism. London: Verso.

Berg M \& Seeber BK (2016) The Slow Professor: Challenging the Culture of Speed in the Academy. Toronto: University of Toronto Press.

Carp J (2012) The study of slow. In Collaborative resilience: moving through crisis to opportunity edited by BE Goldstein. Cambridge: MIT Press, pp. 99-125.

Carrigan M (2016) Social Media for Academics. London: Sage.

Collins H (2014) Are We All Scientific Experts Now? Cambridge: Polity 
Connolly WE (2002) Neuropolitics: Thinking, Culture, Speed. Minneapolis: The University of Minnesota Press.

Flaherty MG (2011) The Textures of Time: Agency and Temporal Experience. Philadelphia: Temple University Press.

Glezos S (2012) The politics of speed: capitalism, the state and war in an accelerating world. London: Routledge.

Hartman Y \& Darab S (2012) A call for slow scholarship: A case study on the intensification of academic life and its implications for pedagogy. Review of Education, Pedagogy, and Cultural Studies 34 (1-2): 49-60.

Harvey D (2006) Limits to Capital. $2^{\text {nd }}$ edition. London: Verso.

Harvey D (2014) Seventeen Contradictions and the End of Capitalism. London: Profile Books.

Heath J \& Potter A (2005) The Rebel Sell. Toronto: HarperCollins.

Honoré C (2004) In Praise of Slow: How a Worldwide Movement is Challenging the Cult of Speed. London: Orion.

Honoré C (2013) The Slow Fix: Solve Problems, Work Smarter, and Live Better in a World Addicted to Speed. New York: HarperCollins. 
Hsu E (2015) The slow food movement and time shortage: Beyond the dichotomy of fast or slow. Journal of Sociology 51(3): 628-642.

Koepnick L (2015) On Slowness: Toward an Aesthetic of the Contemporary. New York: Columbia University Press.

Korunka C \& Hoonakker P (eds) (2014) The Impact of ICT on Quality of Working Life. Dordrecht: Springer

Koselleck R (2004) Futures Past: On the Semantics of Historical Time. New York: Columbia University Press.

Levine R (1997) A Geography of Time: The Temporal Misadventures of a Social Psychologist, or How Every Culture Keeps Time Just a Little Bit Differently. New York: Basic Books.

Levy DM (2007) No time to think: Reflections on information technology and contemplative scholarship. Ethics and Information Technology 9 (4): 237-249.

Mackay R \& Avanessian A (2014) Introduction. In \#Accelerate: The Accelerationist Reader. Falmouth: Urbanomic, pp. 1-46.

MacKenzie D (2014) Be grateful for drizzle. London Review of Books 36 (17): 27-30. 
McIvor D (2011). The politics of speed: Connolly, Wolin, and the prospects for democratic citizenship in an accelerated polity. Polity 43(1): 58-83.

Mountz A et al. (2015). For slow scholarship: a feminist politics of resistance through collective action in the neoliberal university. Forthcoming in Acme: An International E-journal for Critical Geographies, pre-print available at: http://www.researchgate.net/profile/Alison_Mountz/publication/275100129_For_Slo w_Scholarship_A_Feminist_Politics_of_Resistance_through_Collective_Action_in_t he_Neoliberal_University/links/5532d2a20cf27acb0deda012.pdf (retrieved September 2016).

Müller R (2014). Racing for what? Anticipation and acceleration in the work and career practices of academic life science postdocs [43 paragraphs]. Forum Qualitative Sozialforschung / Forum: Qualitative Social Research, 15(3), Art. 15, available at http://nbn-resolving.de/urn:nbn:de:0114-fqs1403150 (last visited December 2015).

Nadolny S (2004) The Discovery of Slowness. London: Canongate.

Noys B (2014) Malign Velocities: Accelerationism and Capitalism. London: Zero Books.

Osbaldiston N (ed.) (2013a) Culture of the Slow: Social Deceleration in an Accelerated World. Basingstoke: Palgrave Macmillan. 
Osbaldiston N (2013b) Slow culture: An introduction. In Culture of the Slow: Social Deceleration in an Accelerated World edited by N Osbaldiston. Basingstoke: Palgrave Macmillan, pp.1-17.

Osbaldiston N (2013c) Conclusion: Departing notes on the slow narrative. In Culture of the Slow: Social Deceleration in an Accelerated World edited by N Osbaldiston. Basingstoke: Palgrave Macmillan, pp.178-192.

Parkins W \& Craig J (2006) Slow Living. Oxford: Berg.

Pels D (1998) Property and Power in Social Theory: A Study in Intellectual Rivalry. London: Routledge.

Pels D (2003) Unhastening Science: Autonomy and Reflexivity in the Social Theory of Knowledge. Liverpool: Liverpool University Press.

Petrini C (2003) Slow Food: The Case for Taste. New York: Columbia University Press.

Piketty T (2014) Capital in the Twenty-First Century. Cambridge: Harvard University Press.

Postone M (1993). Time, labour, and social domination. A reinterpretation of Marx's critical theory. Cambridge: Cambridge University Press. 
Priego E (2013) Predatory journals and defective peer review are general academic problems, not just open access problems. LSE Social Impact Blog, available at http://blogs.lse.ac.uk/impactofsocialsciences/2013/10/07/whos-afraid-of-open-access/ (retrieved September 2016).

Rosa H (2010) Alienation and Acceleration: Towards a Critical Theory of LateModern Temporality. Malmö: NSU Press.

Rosa H (2013) Social Acceleration: A New Theory of Modernity. New York: Columbia University Press.

Rosa H (2014) From work-life to work-age balance? Acceleration, alienation, and appropriation at the workplace. In The Impact of ICT on Quality of Working Life edited by C Korunka and P Hoonakker. Dordrecht: Springer, pp. 43-61.

Rosa H (2015) Capitalism as a Spiral of Dynamisation: Sociology as Social Critique. In Sociology, Capitalism, Critique edited by K Dörre, S Lessenich \& H Rosa. London: Verso, pp. 67-97.

Rosa H, Dörre K and S Lessenich (2016) Appropriation, activation and acceleration: The escalatory logics of capitalist modernity and the crises of dynamic stabilization. Theory, Culture \& Society. DOI: 10.1177/0263276416657600, published online before print 29 July 2016. 
Rosen L (2013) iDisorder: Undertanding our Obsession with Technology and Overcoming its Hold on Us. Basingstoke: Palgrave Macmillan.

Savage M (2014) Piketty's challenge for sociology. British Journal of Sociology 65(4): 591-606.

Saward M (2015) Agency, design and 'slow democracy'. Time \& Society, published online before print as doi: 10.1177/0961463X15584254.

Sayer A (2000) Who is afraid of critical social science? Current Sociology 57 (6): 767-786).

Sayer D (1991) Capitalism and Modernity: An Excursus on Marx and Weber. London: Routledge

Scheuerman WE (2004) Liberal Democracy and the Social Acceleration of Time. Baltimore: The Johns Hopkins University Press.

Schöneck NM (2015) Europeans’ work and life - out of balance? An empirical test of assumptions from the " acceleration debate.' Time \& Society, DOI: 10.1177/0961463X15577286, published online before print 9 April 2015.

Sewell WH (2008) The temporalities of capitalism. Socio-Economic Review 6 (2008): $517-537$. 
Taylor MC (2014) Speed Limits: Where Time Went and Why we Have so Little Left. New Haven: Yale University Press.

Tomlinson J (2007) The Culture of Speed: The Coming of Immediacy. London: Sage.

Vostal F (2014a) Thematizing speed: between critical theory and cultural analysis. European Journal of Social Theory, 17 (1): 95-114.

Vostal F (2014b) Towards a social theory of acceleration: Time, modernity, critique. Revue européenne des sciences sociales 52(2): 235-249.

Vostal F (2015a) Academic life in the fast lane: the experience of time and speed in British academia. Time \& Society, 24 (1): 71-95.

Vostal F (2015b) Speed kills, speed thrills: constraining and enabling accelerations in academic work-life. Globalisation, Societies and Education, 13 (3): 295-314.

Vostal F (2016) Accelerating Academia: The Changing Structure of Academic Time. Basingstoke: Palgrave Macmillan.

Wagner P (1994). A Sociology of Modernity: Liberty and Discipline. London: Routledge.

Wajcman J (2015). Pressed for Time: The Acceleration of Life in Digital Capitalism. Chicago: The University of Chicago Press. 
Williams A \& Srnicek N (2014) \#Accelerate: Manifesto of an Accelerationist Politics. In \#Accelerate: The Accelerationist Reader. Falmouth: Urbanomic, pp. 347-362.

Wolin S (1997) What time is it? Theory \& Event 1(1)

http://muse.jhu.edu/login?auth=0\&type=summary\&url=/journals/theory_and_event/v 001/1.1wolin.html (retrieved September 2016). 